\title{
Pathogenic and genetic diversity among Alternaria alternata isolates of potato from Himachal Pradesh, Madhya Pradesh and Uttar Pradesh
}

\author{
SANJEEV SHARMA*, V. SAGAR, B.P. SINGH, A. JEEVALATHA, GARIMA THAKUR, V.U. PATIL and \\ S.K. CHAKRABARTI \\ ICAR-Central Potato Research Institute, Shimla 171 001, Himachal Pradesh, India
}

Received: 9 February 2017/ Accepted: 20 May 2017/ Published online: 25 May 2017

(C) Indian Phytopathological Society 2017

\begin{abstract}
Early blight of potato caused by species of Alternaria is one of the most important diseases of potato worldwide. The occurrence of $\boldsymbol{A}$. solani and $\boldsymbol{A}$. alternata varies from region to region. The samples were collected from Himachal Pradesh, Uttar Pradesh and Madhya Pradesh states of India during 2009 and 2010. The identity of all the isolates was confirmed as $A$. alternata by morphological characters and sequencing. PCR amplification using universal primers ITS 4 and ITS 5 resulted in an amplicon of 594 bp which showed high similarity with reference ITS sequences of $A$. alternata in GenBank. Analysis of sequences revealed presence of partial sequence of ITS 1 and ITS 2 and complete sequence of 5.8S rRNA gene. All the isolates of $A$. alternata showed $100 \%$ similarity among themselves (except ALT 43 ) and with other $A$. alternata isolates in the GenBank. Three major clusters each were obtained when isolates were genotyped for RAPD and for AFLP markers. Pathogenicity was proved by detached leaf inoculation method and all the isolates were found pathogenic with varying degree of aggressiveness. Isolates were grouped into four groups on the basis of aggressiveness. No correlation was observed between aggressiveness and the clusters made on the basis of genotyping.
\end{abstract}

Keywords: Alternaria alternata, diversity, early blight, Solanum tuberosum

Alternaria species are widely distributed in temperate and tropical regions and are of great economic importance, as they cause leaf spots, blights, blemishes, and damage to stored products (Rotem, 1994; Partap and Solanki, 2016). Severe epidemics due to early blight can lead to major crop losses in short periods of time (Batista et al., 2006). The frequency occurrence of Alternaria species varies from region to region. In Germany, the frequency of Alternaria alternata and $A$. solani on potato is almost equal (Hauslanden and Bassler, 2004) while in Poland the occurrence of $A$. alternata on potato has been reported more than that of $A$. solani (Kapsa, 2007). Environmental conditions are favourable to early blight epidemics wherever potato and tomato are grown but the disease is more severe in the summer, when high temperature and rainfall prevail (Batista et al., 2006). Disease management, especially the strategies related to the deployment of resistant cultivars and fungicide usage, are directly affected by pathogen variation (Milgroom and Fry, 1997; Milgroom and Peever, 2003). Genetic analysis of plant pathogen populations are important in understanding epidemiology, host-pathogen co-evolution, resistance management, and control methods (Aradhya et al., 2001; Morris et al., 2000).

Genetic diversity is the base of evolution of species and populations. Populations with higher genetic diversity

\footnotetext{
${ }^{\star}$ Corresponding author: sanjeevsharma.cpri@gmail.com
}

are stable against changes in environmental conditions (Ayla and Kiger, 1984). Therefore, the first step for managing a plant pathogen is to investigate the diversity. Many Alternaria spp. lack a sexual stage (Berbee et al., 2003). Nevertheless, variability of this asexual species is high (Thomma, 2003) and the first assessment of variation dates back to 1920s (Bonde, 1929). Isolates of $A$. solani and $A$. alternata may vary in virulence, implicating the existence of physiological races within these species. Genetic variation in $A$. solani and $A$. alternata has been examined using biochemical and molecular markers. Petrunak and Christ (1992) investigated the isozyme variability in these two species and found 23 different electrophoretic types for isolates of $A$. alternata and 12 electrophoretic types within a population of $A$. solani. Adachi et al. (1993) classified 271 isolates of $A$. alternata isolated from the Japanese pear into 8 different types based on sequence variation in ribosomal DNA (rDNA). Guo et al. (2004) studied genetic diversity of $A$. alternata isolated from pine using ISSR markers and found that only two primers showed high level of genetic diversity. Zhong-hui et al. (2011) also studied genetic diversity in eight isolates of $A$. alternata at five regions of China on tobacco using ISSR markers. Similarly, Bagherabadi et al. (2015) studied genetic diversity of $A$. alternata on potato using ISSR markers and found narrow range of genetic diversity among potato isolates. Besides, the genetic variation of 
saprobic and pathogenic $A$. alternata isolates has previously been assessed based on the analyses of RAPD, AFLP, RFLP, DNA hybridisation and DNA sequences (Adachi et al., 1993; Aradhya et al., 2001; Morris et al., 2000; Peever et al., 2002; Tanabe et al., 1990). The present study was aimed at to study the genetic and pathogenic variability among isolates of $A$. alternata and to establish the relationship between these groups (genetic and pathogenic groups), if any.

\section{MATERIALS AND METHODS}

\section{Fungal isolates}

A description of isolates used in this study appears in Table 1. Potato/tomato leaves with typical symptoms of early blight were collected from different locations during 2009 and 2010, labelled properly and brought to laboratory for further pathogen isolations. Fragments of

Table 1. Geographic and host plant origins of the A. alternata isolates used in this study

\begin{tabular}{|c|c|c|c|c|c|}
\hline $\begin{array}{l}\text { Isolate } \\
\text { no. }\end{array}$ & Host & Plant part & Geographic origin & $\begin{array}{l}\text { GenBank accession } \\
\text { number }\end{array}$ & $\begin{array}{l}\text { Date of } \\
\text { collection }\end{array}$ \\
\hline ALT 1 & Potato & Leaf & CPRS, Kufri, Shimla (HP) & HM067827 & July, 2009 \\
\hline ALT 2 & Potato & Leaf & CPRS, Kufri, Shimla (HP) & & July, 2009 \\
\hline ALT 3 & Potato & Leaf & CPRS, Fagu, Shimla (HP) & HM114272 & July, 2009 \\
\hline ALT 4 & Potato & Leaf & CPRI, Shimla (HP) & & July, 2009 \\
\hline ALT 5 & Potato & Leaf & CPRI, Shimla (HP) & & July, 2009 \\
\hline ALT 6 & Potato & Leaf & CPRI, Shimla (HP) & & July, 2009 \\
\hline ALT 7 & Potato & Leaf & CPRI, Shimla (HP) & & July, 2009 \\
\hline ALT 8 & Potato & Leaf & CPRS, Kufri, Shimla (HP) & & July, 2009 \\
\hline ALT 9 & Potato & Leaf & CPRS, Fagu, Shimla (HP) & & July, 2009 \\
\hline ALT 10 & Potato & Leaf & CPRS, Fagu, Shimla (HP) & & July, 2009 \\
\hline ALT 11 & Potato & Leaf & CPRS, Fagu, Shimla (HP) & & Aug., 2009 \\
\hline ALT 12 & Potato & Leaf & CPRS, Kufri, Shimla (HP) & & Aug., 2009 \\
\hline ALT 13 & Potato & Leaf & CPRS, Fagu, Shimla (HP) & & Aug., 2009 \\
\hline ALT 14 & Potato & Leaf & CPRS, Kufri, Shimla (HP) & & Aug., 2009 \\
\hline ALT 15 & Potato & Leaf & CPRS, Kufri, Shimla (HP) & & Aug., 2009 \\
\hline ALT 16 & Potato & Leaf & CPRS, Kufri, Shimla (HP) & & Aug., 2009 \\
\hline ALT 17 & Tomato & Leaf & Arki, Solan (HP) & HM114273 & Aug., 2009 \\
\hline ALT 18 & Tomato & Leaf & Arki, Solan (HP) & & Aug., 2009 \\
\hline ALT 19 & Tomato & Leaf & Arki, Solan (HP) & & Aug., 2009 \\
\hline ALT 20 & Potato & Leaf & CPRI (LL), Shimla (HP) & HM114274 & July, 2009 \\
\hline ALT 21 & Potato & Sprout & CPRIC, Modipuram (UP) & HM125062 & Feb., 2010 \\
\hline ALT 22 & Potato & Leaf & CPRI (LL), Shimla (HP) & & July, 2009 \\
\hline ALT 23 & Potato & Leaf & CPRI, Shimla (HP) & HM125063 & July, 2009 \\
\hline ALT 24 & Potato & Leaf & CPRI , Shimla (HP) & & July, 2009 \\
\hline ALT 25 & Potato & Leaf & CPRS, Kufri, Shimla (HP) & & July, 2009 \\
\hline ALT 26 & Potato & Leaf & CPRIC, Modipuram (UP) & HM125064 & Dec., 2009 \\
\hline ALT 27 & Potato & Leaf & CPRIC, Modipuram (UP) & & Dec., 2009 \\
\hline ALT 28 & Potato & Leaf & CPRIC, Modipuram (UP) & & Dec., 2009 \\
\hline ALT 29 & Potato & Leaf & CPRIC, Modipuram (UP) & & Dec., 2009 \\
\hline ALT 30 & Potato & Leaf & CPRIC, Modipuram (UP) & & Dec., 2009 \\
\hline ALT 31 & Potato & Leaf & CPRIC, Modipuram (UP) & & Dec., 2009 \\
\hline ALT 32 & Potato & Leaf & CPRIC, Modipuram (UP) & & Dec., 2009 \\
\hline ALT 33 & Potato & Leaf & CPRIC, Modipuram (UP) & & Dec., 2009 \\
\hline ALT 34 & Potato & Leaf & Indore, MP & HM125065 & Dec., 2009 \\
\hline ALT 35 & Potato & Leaf & Indore, MP & & Dec., 2009 \\
\hline ALT 36 & Potato & Leaf & Ujjain, MP & HM125066 & Dec., 2009 \\
\hline ALT 37 & Potato & Leaf & Indore, MP & & Dec., 2009 \\
\hline ALT 38 & Potato & Leaf & Gwalior, MP & HM125067 & Dec., 2009 \\
\hline ALT 39 & Potato & Leaf & Baddi, Solan (HP) & HM125068 & Jan., 2010 \\
\hline ALT 40 & Potato & Leaf & CPRI, Shimla (HP) & & July, 2009 \\
\hline ALT 41 & Potato & Leaf & CPRS, Kufri, Shimla (HP) & & July, 2009 \\
\hline ALT 42 & Potato & Leaf & CPRS, Kufri, Shimla (HP) & & July, 2009 \\
\hline ALT 43 & Potato & Leaf & CPRS, Fagu, Shimla (HP) & & July, 2009 \\
\hline
\end{tabular}


tissue (2-5 mm long) were cut from the margin of the lesions and transferred to $70 \%$ ethanol for 30 s, disinfected with $1 \%$ sodium hypochlorite for $1 \mathrm{~min}$ and washed twice with distilled sterilized water. The surface disinfested fragments were then placed in Petri-plates (four sections per plate) containing acidified ( $\mathrm{pH}$ adjusted to 6.8 with lactic acid) potato dextrose agar medium (Peeled Potatoes 250 g; agar- agar 17 g; sucrose 15 g; distilled water one litre). After five days of incubation at $24 \pm 1^{\circ} \mathrm{C}$, hyphal tips of fungus growing out of the fragments were excised and transferred again to acidified PDA slants, incubated at $24 \pm 1^{\circ} \mathrm{C}$ for $4-5$ days and then maintained at $4^{\circ} \mathrm{C}$ in a refrigerator. The identity of these isolates was confirmed by morphological characters according to descriptions of Simmons (1999).

\section{DNA extraction}

Each isolate was grown in $50 \mathrm{ml}$ of potato dextrose broth in $150 \mathrm{ml}$ Erlenmeyer flasks under continuous agitation (100 rev $\mathrm{min}^{-1}$ ) at $24 \pm 1^{\circ} \mathrm{C}$ for seven days. Mycelium was harvested by filtration, washed with distilled sterilized water, transferred to filter paper to dry, ground in a mortar with liquid nitrogen to fine powder and stored at $-20 \pm 1^{\circ} \mathrm{C}$ until further use. Total genomic DNA was extracted using Plant Genomic DNA Mini Prep kit (Gen Elute ${ }^{T M}$, Sigma Life Sciences) following the manufacturer's guidelines.

\section{DNA amplification and sequencing}

Partial sequences of the ITS region were amplified using fungal specific primers ITS4 (5'TCC TCC GCT TAT TGA TAT GC3') and ITS5 (5'GGA AGT AAA AGT CGT AAC AAG G3') by polymerase chain reaction (White et al., 1990). All amplification reactions were performed in a $25 \mu \mathrm{l}$ reaction volume which contained $200 \mu \mathrm{M}$ of each dNTP, $50 \mathrm{mM} \mathrm{KCl}, 10 \mathrm{mM}$ Tris- $\mathrm{HCl}\left(\mathrm{pH} 9.0\right.$ at $\left.25^{\circ} \mathrm{C}\right), 1.5$ $\mathrm{mM} \mathrm{MgCl}_{2}, 0.1 \%$ Triton(R) X-100, $0.5 \mu \mathrm{M}$ of each primer, 1 unit Taq DNA Polymerase (Promega), and $50 \mathrm{ng}$ template DNA. The PCR reaction was performed for 35 cycles with an initial $5 \mathrm{~min}$ at $94^{\circ} \mathrm{C}$ for denaturation and a final $7 \mathrm{~min}$ at $72^{\circ} \mathrm{C}$ for the extension in a GeneAmp PCR System 9700 . Each cycle consisted of $35 \mathrm{~s}$ at $94^{\circ} \mathrm{C}$, $55 \mathrm{~s}$ at $60^{\circ} \mathrm{C}$ and $1 \mathrm{~min}$ at $72^{\circ} \mathrm{C}$. Successful amplification was checked by electrophoresis in a $1 \%$ agarose gel at $100 \mathrm{~V}$ in 1 XTBE buffer at room temperature. Fragments were visualized under UV light after staining with ethidium bromide and photographed. All reactions were repeated at least twice including negative controls (no template DNA).

Purified amplicons were sequenced using ABI Prism 310 Genetic Analyzer (v3.1; Applied Biosystems). Sequences of each isolate were manually edited using The Staden Package, ver 1.6.0 to generate a consensus sequence. All polymorphisms were rechecked from the chromatograms. Sequences were aligned and phylogenetic tree was constructed using Clustal $X$. The BioEdit programme was used to prepare similarity identity matrix. All the ITS sequences were identical and one sequence was used as query sequence to search for similar sequences from GenBank using BLAST programme. Concurrently, 11 isolates (one from each location/ host/ plant part) were randomly selected and the ITS (ITS 1, 5.8s, ITS2) sequences were submitted in GenBank at the National Centre for Biotechnology Information (NCBI). A phylogenetic tree was constructed, and a bootstrapped consensus dendrogram was generated with 1000 replications using neighbour joining algorithm of MEGA-4 software.

\section{RAPD analysis}

PCR for RAPD analysis was carried out using 10-mer oligonucleotide primer obtained from Operon Technologies, Alameda. Twenty primers were used for PCR amplification. PCR was carried out in a reaction volume of $25 \mu \mathrm{l}$ containing $10 \mathrm{mM}$ Tris $\mathrm{HCl}(\mathrm{pH}$ 8.3); 50 $\mathrm{mM} \mathrm{KCl}, 0.1 \%$ Triton $\times 100,2.5 \mathrm{~mm} \mathrm{MgCl} ; 200 \mu \mathrm{M}$ each dNTPs, 25 pmol primer, 100 ng genomic DNA; and 1 unit of Taq DNA polymerase. Samples were carried through 40 cycles on Gene Amp PCR System 9700 (Applied Biosystem) by using the following temperature sequence: $94^{\circ} \mathrm{C}$ for $1 \mathrm{~min}, 36^{\circ} \mathrm{C}$ for $1 \mathrm{~min}$ and $72^{\circ} \mathrm{C}$ for 2 $\mathrm{min}$. Cycles were preceded by denaturation for $5 \mathrm{~min}$ at $94^{\circ} \mathrm{C}$ and followed by a final extension cycle at $72^{\circ} \mathrm{C}$ for $10 \mathrm{~min}$. Post-PCR processing analysis was performed on Agilent 2100 Bioanalyser (Agilent Technologies, USA) according to the manufacturer's instructions using DNA 7500 kit. DNA fragments (alleles) were sized automatically using the 2100 Expert software B.02.08. Sl648.

\section{AFLP analysis}

AFLP profiles were generated for 20 isolates. Isolates were grown and treated as previously described for DNA isolation. AFLP genotyping was done using EcoRI and Msel restriction endonucleases, adapters, and primers as described by Vos et al. (1995). Pre-selective amplification was done using no selective nucleotides $($ Eco+0/Mse+0). Total DNA $(0.5 \mu \mathrm{g})$ was digested in a 20 $\mu \mathrm{l}$ volume with $0.5 \mathrm{U}$ each of $\mathrm{EcoRI}$ and Msel and then ligated to EcoRI ND Msel-adaptors along with $0.5 \mathrm{M} \mathrm{NaCl}$ and $1 \mathrm{mg} / \mathrm{ml} \mathrm{BSA}$. After incubation at $37^{\circ} \mathrm{C}$ for $2 \mathrm{~h}$, the reaction mixture was diluted with $180 \mu \mathrm{l}$ TE 0.1 buffer to make final volume $200 \mu \mathrm{l}$. Fragments that had ligated to each of the two adaptors were pre-selectively amplified in $200 \mu \mathrm{l}$ reactions using pre-selective primer pairs using ligation and pre-selective amplification module complimentary to the adaptor sequences and selective PCR was then performed using selective amplification start up module with primer combinations (Msel- A/C/G/ $T$ \& EcoRI- AT/AC/AG) in $20 \mu \mathrm{l}$ volumes using an appropriate pair of primers. Out of 12 primer combinations, primers which showed polymorphic bands were selected for analysis. AFLP fragments were resolved and analyzed on capillary based genetic analyzer (ABI Prism 310 Genetic Analyzer, v3.1; Applied Biosystems) following the manufacturer's protocols. AFLP profiles were generated twice for each isolate using independent DNA extractions. The generated signals were analyzed by using Gene Scan analysis. A binary matrix was constructed using only clearly resolved, replicated markers. 


\section{Pathogenicity test}

Inoculum production: Mycelial bits from stock cultures of each isolate were transferred aseptically to fresh PDA Petri-plates and incubated at $24 \pm 1^{\circ} \mathrm{C}$ in dark. Conidia from 7 days old cultures were washed off with distilled sterilized water and filtered through muslin cloth of 0.1 $\mathrm{mm}$ diameter mesh size. The conidial suspension was then shaken and supplemented with Tween-20@10 $\mathrm{ll}$ $\mathrm{I}^{-1}$ and concentration was determined using a haemocytometer and adjusted to $5 \times 10^{4}$ conidia $\mathrm{ml}^{-1}$.

Detached leaf inoculation test: Certified seed tubers of Solanum tuberosum cv. Kufri Jyoti were planted in a glass house. Pathogenicity was tested on detached leaflets (40 days after planting). The first pair of fully expanded leaflets (3 replications) was removed and placed in plastic boxes lined with moist towelling. Injury was caused by needle at three points on one side of the midrib and immediately inoculated by using micropipette to place $10 \mu \mathrm{l}$ droplet of the $A$. alternata isolate spore suspension. The other side of the midrib received a 10 $\mu \mathrm{l}$ droplet of the inoculum without injury. Leaflets receiving only sterile water droplets were treated as control. The boxes were sealed with para-film and placed in an incubator at $25 \pm 1{ }^{\circ} \mathrm{C}$ and 16 -h photoperiod. The leaflets were observed regularly for the appearance of symptoms and lesion area (LA) was computed by measuring length and breadth of each lesion daily after determination of incubation period by substituting these measurements into the equation for an ellipse (Birhman and Singh, 1995) as lesion area $(L A)=\pi / 4^{\star} a b$, where, $a=$ length and $b=$ breadth of the lesion.

\section{Data analysis}

DNA fragment profiles were scored in a binary fashion with 0 indicating absence and 1 indicating presence of a band. A similarity matrix on the basis of band sharing was calculated from the binary data using Dice coefficient (Nei and Li, 1979). Dendrogram was generated with the help of DARwin 6.0.11using bootstrap and Neighbor joining methods (Perrier Jacquemoud-Collet, 2006).

\section{RESULTS}

\section{DNA amplification and sequencing}

PCR amplification, using universal primers ITS 4 and ITS 5, resulted in an amplicon of 594bp in all the isolates. The fragments were sequenced using forward primer and their identity confirmed through BLAST analysis. The results indicated that these sequences had high similarity with reference ITS sequences of $A$. alternata in GenBank. The ITS region of the Alternaria isolates from India shared $99.6-100 \%$ similarity to ITS regions of Alternaria alternata, A. tennuissima and $A$. brassicae while it was distinctly related to $A$. solani with $93.2-94.7 \%$ similarity. The sequences of representative isolates were submitted in NCBI (Table 1). Analysis of sequence revealed presence of partial sequence of ITS 1 and ITS 2 and complete sequence of 5.8S rRNA gene. All the isolates of $A$. alternata showed $100 \%$ similarity among themselves (except ALT 43) and with other A. alternata isolates in the GenBank and with some uncultured isolates (Fig. 1). The A. alternata isolates were clearly different from the sequences of $A$. solani isolates (Fig. 1).

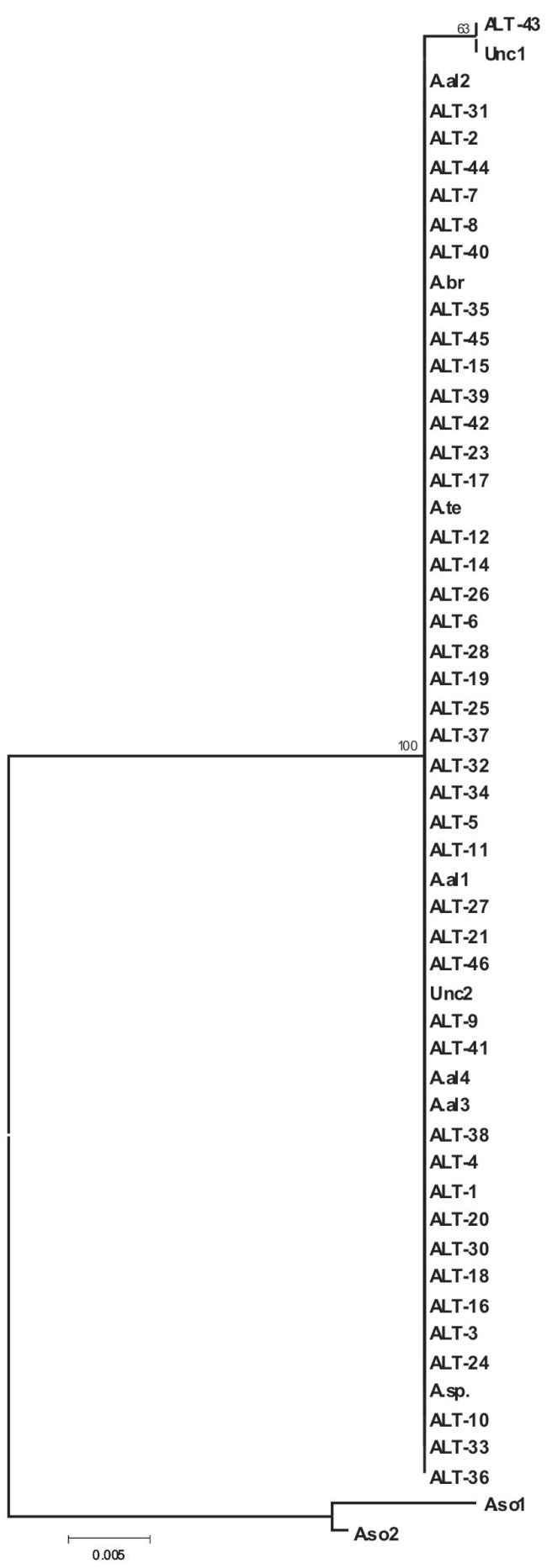

Fig. 1. Phylogenetic dendrogram based on the ITS region of Alternaria alternata isolates from potato with other related isolates from NCBI. (Unc1- Uncultured endophytic fungus, EF504739; Unc2- Uncultured root associated fungus, FJ362184; A. al3- Alternaria alternata, GQ220708; A. teAlternaria tenuissima, GQ871507; A. al4- Alternaria alternata, AB470832; A.br- Alternaria brassicae, EU520252; A. al1- Alternaria alternata, GU205188; A. al2Alternaria alternata, GU062279; A. sp.- Alternaria sp., GQ302684; A. so1- Alternaria solani, AF229475; A. so2Alternaria solani, EU617717) 
Table 2. RAPD primer sequences that show polymorphism in A. alternata

\begin{tabular}{ll}
\hline Name of primer & Sequence \\
\hline OPA-02 & 5'-TGCCGAGCTG-3' \\
OPA-03 & 5'-AGTCAGCCAC-3' \\
OPA-09 & 5'-GGGTAACGCC-3' \\
OPA-10 & 5'-GTGATCGCAG-3' \\
OPA-11 & 5'-CAATCGCCGT-3' \\
OPA-13 & 5'-CAGCACCCAC-3' \\
OPA-14 & 5'-TCTGTGCTGG-3' \\
OPA-15 & 5'-TTCCGAACCC-3' \\
OPA-18 & 5'-AGGTGACCGT-3 \\
OPA-19 & 5'-CAAACGTCGG-3' \\
\hline
\end{tabular}

\section{RAPD analysis}

Genomic DNA was amplified from 43 isolates using RAPD-PCR analysis. Of 20 primers screened, 10 primers (Table 2) produced reproducible polymorphic banding patterns. A total of 964 bands were scored and the size of the products was within the range of $89 \mathrm{bp}$ to $9338 \mathrm{bp}$. When fingerprints of these isolates were compared, some bands common to all isolates were observed, while others were unique to one or a few isolates. All the 43 isolates were divided into three major clusters (Fig. 2). Seven isolates were grouped into cluster I, 11 in cluster II and 25 in cluster III. No grouping was formed as per the origin of the isolates.

\section{AFLP analysis}

The sub set of isolates (20) was analysed for AFLP. The four combinations were used to amplify the genomic DNA of selected isolates. A total of 437 bands were scored and the number of amplified products generated by each primer varied from 92 to 182, and the size of the products was within the range of $51 \mathrm{bp}$ to $379 \mathrm{bp}$. Cluster analysis could separate 20 isolates into 3 major groups but no correlation was observed between isolates and geographical origin (Fig. 3).

\section{Pathogenicity}

Pathogenicity was proved by detached leaf inoculation method on cv. Kufri Jyoti. The first method of inoculation (injury inoculated) was found superior as it produced clear and early symptoms. Hence, data of this method were included only. All the isolates were found pathogenic with varying degrees of aggressiveness. No differences in lesion area were observed between potato and tomato isolates. The analysis of lesion progression demonstrated highly significant differences among isolates (data not shown). No symptoms were observed after 3 days of inoculation by seven isolates (ALT 2, ALT 4, ALT 7, ALT 18, ALT 21 \& ALT 26), whereas rest of the isolates could produce the symptoms. Five isolates (ALT 11, ALT 14, ALT 10, ALT 25 \& ALT 34) produced smaller lesion area after 3 days of inoculation. Maximum lesion area (6.3 $\mathrm{mm}^{2}$ ) was produced by the isolate ALT 36 followed by ALT 30 after 3 days of inoculation. Irrespective of the interval, highest lesion area $\left(6.7 \mathrm{~mm}^{2}\right)$ was recorded with the isolate ALT 29, followed by the isolate ALT 36 and 41

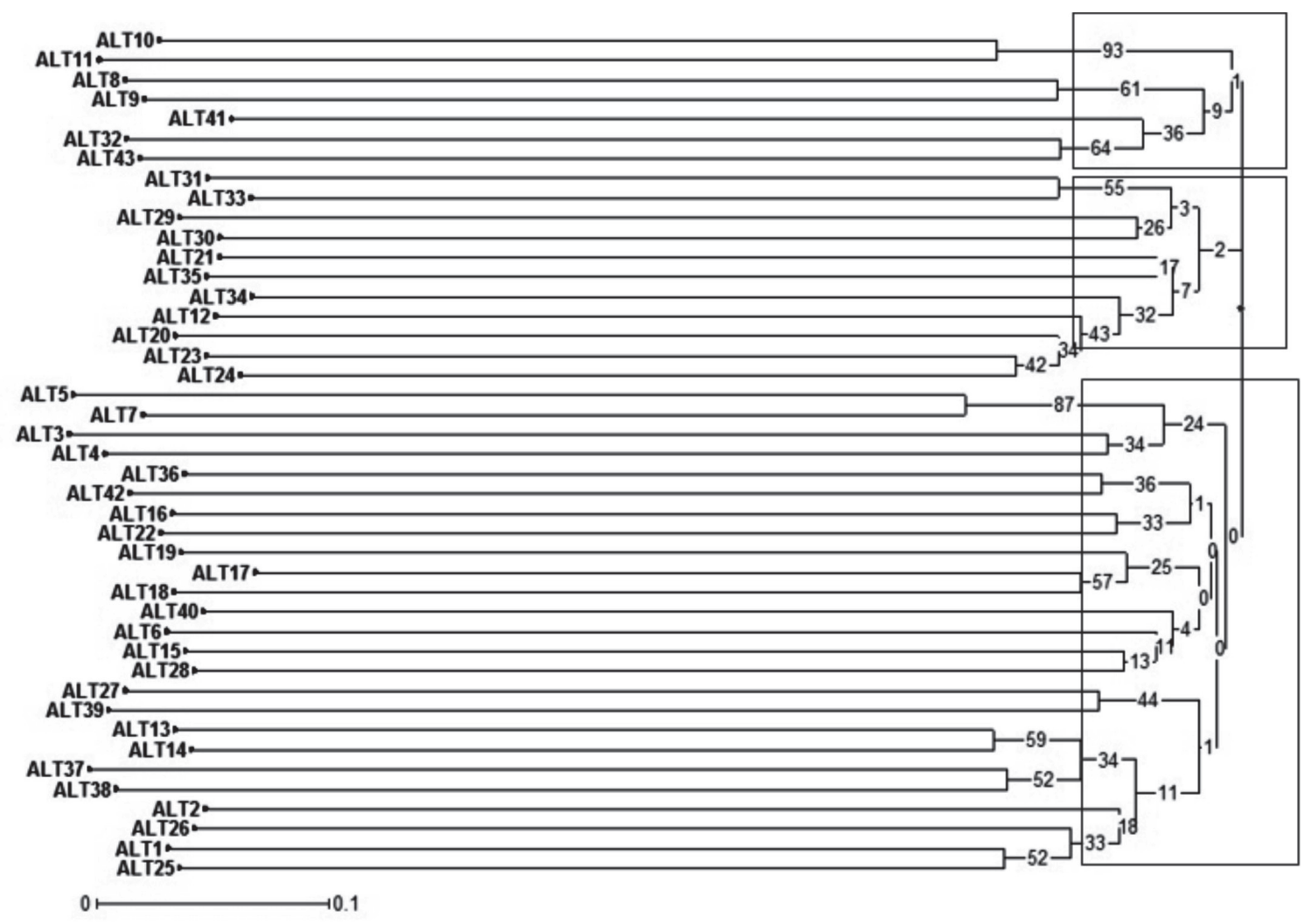

Fig. 2. Dendrogram of $A$. alternata isolates based on RAPD markers using UPGMA cluster analysis 


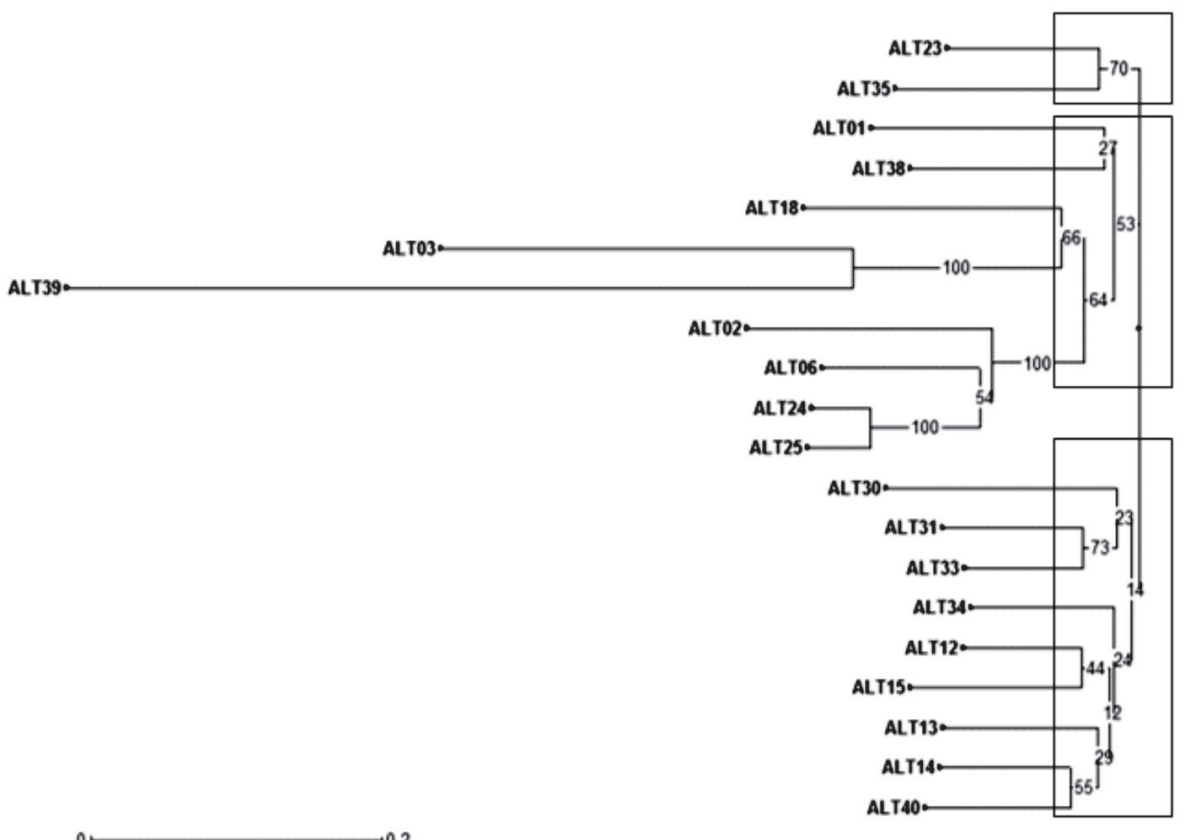

Fig. 3. Dendrogram of $A$. alternata isolates based on AFLP markers using UPGMA cluster analysis

$\left(6.5 \mathrm{~mm}^{2}\right)$, and ALT $43\left(6.2 \mathrm{~mm}^{2}\right)$. On the other hand, least lesion area $\left(0.4 \mathrm{~mm}^{2}\right)$ was produced by the isolate ALT 26 followed by ALT 11 $\left(0.7 \mathrm{~mm}^{2}\right)$ and ALT $5\left(0.9 \mathrm{~mm}^{2}\right)$. On the basis of lesion area, isolates were grouped into different categories. Three isolates (ALT 5, ALT 11 and ALT 26) were found least aggressive as they could produce lesion area of $<1.0 \mathrm{~mm}^{2}$. Nine isolates were grouped into the category of moderately aggressive as they could produce the lesion area of $1.0-2.5 \mathrm{~mm}^{2}, 19 \mathrm{in}$ the category of aggressive as lesion area produced by the isolates ranged from $2.51-5.00 \mathrm{~mm}^{2}$ while 11 were categorised as highly aggressive as they produced lesion area $>5.00 \mathrm{~mm}^{2}$ (Table 3).

\section{DISCUSSION}

The phylogenetic tree constructed based on the ITS region was consistent with morphological numerical taxonomy and traditional classification. Although genotypic differences have not been established for these isolates, the presence of multiple strains of $A$. solani in potato growing regions is not uncommon (Van der Walls et al., 2004). Isolates from the same host, such as potato, have been found to be more closely related to one another than those collected from another host, such as tomato (Weir et al., 1998). But the results of present study are contrary to this. The genetic variability among the isolates of the same host (potato) is due to differences in aggressiveness which is of interest and warrants further study.

There is evidence for the existence of $A$. solani populations associated with potato and tomato plants based on the analysis of phenotypic and molecular markers and could differentiate between the potato and tomato populations of $A$. solani (Martinez et al., 2004; Petrunak and Christ, 1992; Weir et al., 1998). A. solani population have been described as highly variable by assessing genetic variation through RAPD, RAMS and AFLP markers outside the country (Kumar et al., 2008; Martinez et al., 2004; Van der Walls et al., 2004; Weir et al., 1998).

This study has shown relatively high genetic diversity (based on RAPD and AFLP) among A. alternata isolates for an asexually reproducing fungus. Furthermore, there is no clear clustering of isolates according to geographical origin or aggressiveness. The high levels of genetic diversity found among isolates of $A$. alternata could be natural chance mutations, combined with the fact that the fungus can produce abundant spores in a relatively short period of time (Leung et al., 1993; Petrunak and

Table 3. Progression of lesion area of Alternaria alternata isolates on detached leaves

\begin{tabular}{lll}
\hline Lesion area $\left(\mathrm{mm}^{2}\right)$ & Isolate & Aggressiveness category \\
\hline$<1.0$ & ALT 5, ALT 11, ALT 26 & Least aggressive \\
$1.1-2.50$ & ALT2, ALT 7, ALT10, ALT 14, ALT 15, ALT 18, ALT 19, ALT 28, ALT 37 & Moderately aggressive \\
$2.51-5.00$ & ALT 1, ALT 3, ALT 4, ALT 6, ALT 8, ALT 12, ALT 13, ALT 16, ALT 17, ALT 20, & Aggressive \\
& ALT 21, ALT 22, ALT 23, ALT 24, ALT 25, ALT 31, ALT 34, ALT 35, ALT 38 & Highly aggressive \\
& ALT9, ALT 27, ALT 29, ALT 30, ALT 32, ALT 33, ALT 36, ALT 40, ALT 41, & \\
\hline
\end{tabular}


Christ, 1992). Previous studies on A. solani population in the USA and South Africa have also shown no geographical clustering of isolates (Petrunak and Christ, 1992; Weir et al., 1998; Van der Walls et al., 2004). The results show that the various geographical subpopulations are not genetically isolates, which may be ascribed to dissemination of spores by biotic and abiotic factors.

\section{REFERENCES}

Adachi Y, Wantanabe H, Tanabe K, Doke N, Nishimura S and Tsuge, T (1993). Nuclear ribosomal DNA as a probe for genetic variability in the Japanese pear pathotype of Alternaria alternata. App. Environ. Microbiol. 59: 31973205.

Aradhya MK, Chan HM and Parfitt DE (2001). Genetic variability in the pistachio late blight fungus, Alternaria alternata. Mycol. Res. 105: 300-306.

Ayla FJ and Kiger JA (1984). Modern Genetics. $2^{\text {nd }}$ edition. California USA: Benjamin/Cummings, Menlo Park.

Bagherabadi S, Zafari D and Soleimani MJ (2015). Genetic diversity of Alternaria alternata isolates causing potato brown leaf spot using ISSR markers in Iran. J. Plant Pathol. Microb. 6: 286 doi:10.4172/2157-7471.1000286.

Batista DC, Lima MA, Haddad F, Maffia LA and Mizubuti ESG (2006). Validation of decision support systems for tomato early blight and potato late blight, under Brazilian conditions. Crop Prot. 25: 664-670.

Berbee ML, Payne BP, Zhang G, Roberts RG and Turgeon BG (2003). Shared ITS DNA substitutions in isolates of opposite mating type reveal a recombining history of three presumed asexual species in the filamentous ascomycete genus Alternaria. Mycol. Res. 107: 169-182.

Birhman RK and Singh BP (1995). Path-coefficient analyses and genetic parameters of the components of field resistance of potatoes to late blight. Ann. Appl. Biol. 127: 353-362.

Bonde R (1929). Physiological strains of Alternaria solani. Phytopathology 19: 533-548.

Guo LD, Xu L, Zheng WH and Hyde KD (2004). Genetic variation of Alternaria alternata, an endophytic fungus isolated from Pinus tabulaeformis as determined by random amplified microsatellites (RAMS). Fungal Diver. 16: 53-65.

Hauslanden $\mathrm{H}$ and Bassler E (2004). Early blight disease in potatoes. What are the causes? Kartaffelbau 6: 210-212.

Kapsa J (2007). Application of the Burkard spore trap to determine a composition of the genus Alternaria in potato crops. Biuletyn-Instytutu Hodowli-i- Aklimatyazacji-Roslin 244: 223-229.

Kumar V, Haldar S, Pandey KK, Singh RP, Singh AK and Singh PC (2008). Cultural, morphological, pathogenic and molecular variability amongst tomato isolates of Alternaria solani in India. World J. Microbiol. Biotechnol. 24: 10031009.

Leung H, Nelson RJ and Leach JE (1993). Population structure of plant pathogenic fungi and bacteria. Adv. Plant Pathol. 10: 157-205.
Martinez SP, Snowdon R and Pons-Kuhnemann J (2004). Variability of Cuban and international populations of Alternaria solani from different hosts and localities: AFLP genetic analysis. Eur. J. Plant Pathol. 110: 399-409.

Milgroom MG and Fry WE (1997). Contributions of population genetics to plant disease management. Adv. Bot. Res. 24: 1-30.

Milgroom MG and Peever TL (2003). Population biology of plant pathogens. The synthesis of plant disease epidemiology and population genetics. Plant Dis. 87: 608-617.

Morris PF, Connolly MS and St Clair DA (2000). Genetic diversity of Alternaria alternata isolated from tomato in California assessed using RAPDs. Mycol. Res. 104: 286-292.

Nei M and Li WH (1979). Mathematical modeling for studying genetic variation in terms of restriction endonucleases. Proc. Natl. Acad. Sci. USA 74:5267.

Partap, Mahendra and Solanki VA (2016). Impact of black point incited by Alternaria alternata on wheat trade, seed quality and seed germination. Indian Phytopath. 69: 74-76.

Peever TL, Ibanez A, Akimitsu K and Timmer LW (2002). Worldwide phylogeography of the citrus brown spot pathogen, Alternaria alternata. Phytopathology 92: 794802.

Perrier X and Jacquemoud-Collet JP (2006). DARwin software. http://darwin.cirad.fr/darwin.

Petrunak DM and Christ BJ (1992). Isozyme variability in Alternaria solani and A. alternata. Phytopathology 82: 1343-1347.

Rotem J (1994). The genus Alternaria: Biology, Epidemiology, and Pathogenicity. American Phytopathological Society, St. Paul, MN.

Simmons EG (1999). Alternaria themes and variations (236243). Mycotaxon 70: 325-369.

Tanabe K, Tsuge T and Nishimura S (1990). Potential application of DNA restriction fragment length polymorphisms to the ecological studies of Alternaria alternata Japanese pear pathotype. Ann. Phytopathol. Soc. Japan 55: 361-365.

Thomma BPHJ (2003). Alternaria spp.: From general saprophyte to specific parasite. Mol. Plant Pathol. 4: 225-236.

Van der Walls JE, Korsten L and Slippers B (2004). Genetic diversity among Alternaria solani isolates from potatoes in South Africa. Plant Dis. 88: 959-964.

Vos P, Hogers R, Bleeker M, Reijans M, Lee TV, Hornes M, Frijters A, Pot J, Peleman J, Kuiper M and Zabeau M (1995). AFLP: a new technique for DNA fingerprinting. Nucleic Acids Res. 23: 4407-4414.

Weir TL, Huff DR, Christ BJ and Romaine CP (1998). RAPDPCR analysis of genetic variation among isolates of Alternaria solani and $A$. alternata from potato and tomato. Mycologia 90: 813-821.

White TJ, Bruns T, Lee S and Taylor J (1990). Amplification and direct sequencing of fungal ribosomal RNA genes for phylogenetics. In: PCR protocols: a guide to methods and applications (Inns, MA, Gelfand DH, Sninsky JJ and White TT, Eds.), Academic Press, New York, 315-322 pp.

Zhong-hui H, Li-hua Z, Ai-zi T, Lian-chun W, Bao-hua K, Hong C, Jing-hua F, Hai-ru C and Xi-yun Q (2011). Optimization of ISSR-PCR reaction system for Alternaria alternata in tobacco. J. Yunnan Agric. Univ. 5: 602-606. 